\title{
Electrospinning, Characterization and In Vitro Biological Evaluation of Nanocomposite Fibers Containing Carbonated Hydroxyapatite Nanoparticles
}

\author{
Ho-Wang Tong ${ }^{1}$, Min Wang ${ }^{1,}{ }^{*}$, Zhao-Yang $\mathrm{Li}^{2}$, William W. Lu ${ }^{2}$ \\ 1 Department of Mechanical Engineering \\ Faculty of Engineering \\ The University of Hong Kong \\ Pokfulam Road, Hong Kong \\ 2 Department of Orthopaedics and Traumatology \\ Li Ka Shing Faculty of Medicine \\ The University of Hong Kong \\ Sassoon Road, Hong Kong
}

Keywords: electrospinning, poly(hydroxybutyrate-co-hydroxyvalerate) (PHBV), carbonated hydroxyapatite (CHA), nanoparticles, nanocomposite, tissue engineering scaffold

* Correspondence to: Prof. M. Wang at the University of Hong Kong, Hong Kong Fax: +852 $28585415 \quad$ Tel: +85228597903Ｅmail: memwang@hku.hk 


\begin{abstract}
Poly(hydroxybutyrate-co-hydroxyvalerate) (PHBV) fibers containing carbonated hydroxyapatite (CHA) nanoparticles with different CHA amounts $(5,10$, and 15 wt.\%) were electrospun with the aid of ultrasonic power for dispersing the nanoparticles. Scanning electron microscopy and energy-dispersive X-ray spectroscopy results showed that the distribution of CHA within the CHA/PHBV nanocomposite fibers was homogeneous when the CHA content was 10 wt.\%. Slight particle agglomeration occurred when the CHA content was 15 wt.\%. The diameters of the electrospun $\mathrm{CHA} / \mathrm{PHBV}$ nanocomposite fibers and PHBV polymer fibers were around $3 \mu \mathrm{m}$. Fourier transform infrared spectroscopic analysis further confirmed the presence of $\mathrm{CHA}$ in $\mathrm{CHA} / \mathrm{PHBV}$ nanocomposite fibers. Both PHBV and CHA/PHBV fibrous membranes exhibited similar tensile properties. Compared with PHBV solvent-cast film, the PHBV fibrous membrane was hydrophobic but the incorporation of CHA nanoparticles dramatically enhanced its wettability. In vitro studies revealed that both types of electrospun fibrous membranes (PHBV and CHA/PHBV) supported the proliferation of human osteoblastic cells (SaOS-2). The alkaline phosphatase activity of SaOS-2 cells seeded on the CHA/PHBV fibrous membranes was higher than that of the cells seeded on the PHBV fibrous membranes after 14 days of cell culture. The electrospun CHA/PHBV nanocomposite fibrous membranes show promises for bone tissue engineering applications.
\end{abstract}




\section{Introduction}

Electrospinning has been widely investigated in recent years for constructing fibrous tissue engineering scaffolds because electrospun fibers can mimic the cellular microenvironment and hence enhance cell attachment and adhesion [1,2]. While natural, biodegradable polymers such as poly(hydroxybutyrate-cohydroxyvalerate) (PHBV) have been electrospun into fibrous scaffolds in various tissue engineering studies [3-5], these scaffolds lack osteoconductivity that is desired for bone tissue engineering. A polymer-based scaffold can be osteoconductive if the scaffold contains a sufficient amount of bioactive bioceramics such as hydroxyapatite (HA) [6]. Therefore, the incorporation of HA particles into electrospun fibers to form HA/polymer composite fibrous scaffolds have been investigated by various research groups. Kim et al. electrospun polyvinyl alcohol (PVA) nanofibers containing HA nanoparticles, which closely mimicked the mineralized hard tissues of bones in the biological system [7]. Luong et al. modified the surface of the electrospun poly(L-lactic acid) (PLLA) fibers by incorporating HA nanocrystals (30 nm in diameter and 100-120 nm in length) and reported that the modified fibers had higher surface energy and lower water contact angle, which should enhance cell attachment due to the high hydrophilicity [8]. Nie et al. developed HA/poly(lactic-co-glycolic acid) (PLGA) composite fibrous scaffolds loaded with recombinant human bone morphogenetic protein-2 and demonstrated that the encapsulation of HA into the fibers could enhance attachment of marrow derived mesenchymal stem cells and reduce cytotoxicity of the fibrous scaffolds [9]. Wang et al. electrospun HA/PLLA fibrous biomaterials and found that the human periodontal ligament cells could attach and proliferate well on the fibrous biomaterials [10]. Zhang et al. incorporated HA nanoparticles into electrospun chitosan nanofibers and assessed their biological properties using human fetal osteoblast cells [11]. They reported that the incorporation of HA could lead to significant bone formation. Gupta et al. fabricated composite fibrous scaffolds of poly(L-lactic acid)-co-poly( $\varepsilon$-caprolactone) (PLACL), gelatin and HA by combining the electrospinning and electrospraying techniques. Compared with the PLACL/gelatin scaffolds without HA, they found that the HA-sprayed scaffolds could not only show better proliferation of human fetal osteoblast cells but also enhance mineralization and alkaline phophatase activity, which implied the 
potential of HA-sprayed scaffolds for bone tissue regeneration [12]. Guan et al. made polyhydroxybutyrate (PHB) fibrous scaffolds containing HA nanoparticles through electrospinning and found that the composite scaffolds exhibited positive effects on the attachment, proliferation and differentiation of bone marrow stroma cells in vitro [13]. Asran et al. incorporated HA nanoparticles into electrospun polyvinyl alcohol (PVA) / Type I collagen fibers and found that the nanostructure of the biocomposite fibers was similar to that of bone [14]. Chuenjitkuntaworn et al. electrospun PLLA fibrous scaffolds containing HA nanoparticles and found that the scaffolds could not only facilitate attachment and proliferation of mouse pre-osteoblastic cells but also enhance the expression of osteocalcin and mineralization [15].

Carbonated HA (CHA) is a proven osteoconductive and biodegradable bioceramic. CHA nanoparticles, which resemble bone apatite more chemically and possess higher resorption rate than HA nanoparticles, are more suitable than pure HA for bone tissue engineering applications $[16,17]$. They may be incorporated in tissue engineering scaffolds, thus rendering the scaffolds osteoconductive and also totally biodegradable. It is worth noting that the surface area of CHA nanoparticles synthesized through a nanoemulsion process could reach $50 \mathrm{~m}^{2} / \mathrm{g}$ [18], which is much higher than that of the commercial nanosized HA powders. The high surface area-to-mass ratio of these CHA nanoparticles is well suited for constructing nanocomposite scaffolds for bone tissue engineering. However, the agglomeration of the nanoparticles in the polymer solution is a common problem during the electrospinning process. To date, it is still a challenge to incorporate substantial amounts of HA particles into electrospun fibers because fine (micro- or nano-size) HA particles tend to agglomerate together [6]. Jose et al. tried to electrospin poly(lactic-co-glycolic acid) (PLGA) fibers with different amounts of HA nanoparticles (1 to 20 wt.\%) and observed severe agglomeration of HA nanoparticles [19]. The problem of HA particle agglomeration causes reduced electrospinning efficiency, reduced nanoparticles loading capacity, poor dispersion of nanoparticles within fibrous scaffolds, and weak scaffolds. Some researchers tried to mix surfactants with the polymer solution before electrospinning in order to prevent the agglomeration of HA particles [20]. But the use of additives could cause biocompatibility problems due to possible cytotoxicity of the 
additives. Therefore, it is ideal that the use of additives is kept to minimum or totally avoided when constructing fibrous tissue engineering scaffolds via electrospinning. In the present study, possible techniques to uniformly disperse substantial amounts of CHA nanoparticles in electrospun PHBV fibers without the use of additives were investigated. The electrospun PHBV fibrous polymer membranes and CHA/PHBV fibrous nanocomposite membranes were subjected to various biological evaluations for their potential applications in bone tissue engineering.

\section{Materials and methods}

\subsection{Electrospinning of PHBV polymer and CHA/PHBV nanocomposite fibrous membranes}

PHBV with $5 \mathrm{~mol} \%$ of hydroxyvalerate (Sigma-Aldrich, USA) was dissolved in chloroform (analytical grade) at a polymer concentration of $15 \% \mathrm{w} / \mathrm{v}$. The CHA nanoparticles used for constructing nanocomposite fibers were synthesized in-house through a nanoemulsion process which is similar to the process developed in a previous study [18]. PHBV fibers without CHA were electrospun using the facility described previously [21]. Attempts were made to fabricate CHA/PHBV nanocomposite fibers with CHA content of 5, 10 and 15 wt.\% by electrospinning via three routes (figure 1). In Route I, the CHA nanoparticles were mixed with the polymer solution by a magnetic stirrer and the mixture was then subjected to the electrospinning process. This was a two-step process for producing nanocomposite fibers

(figure $1(A)$ ). In Route II, the mixture consisting of the CHA nanoparticles and polymer solution was sonicated by ultrasound energy for 30 minutes before electrospinning. This was also a two-step process (figure $1(B)$ ). In Route III, ultrasound energy was applied directly to the mixture by an ultrasonic cell disruptor during the electrospinning process. This was considered to be a one-step process (figure $1(C)$ ). PHBV films were made and the wettability of these films was compared with that of PHBV fibers. Solvent-casting technique was employed to fabricate PHBV films. First, the above-mentioned PHBV solution was transferred to a Petri dish. Then the Petri dish was gently shaken for 3 minutes such that the surface of the PHBV solution became flat and smooth. After that, the Petri dish was kept in a fume hood 
until the solvent (i.e. chloroform) was completely evaporated. Finally, a PHBV film could be peeled off from the Petri dish and used for wettability evaluation.

\subsection{Characterization}

The fiber forming efficiencies were compared among these three approaches. Both electrospun PHBV polymer fibers and CHA/PHBV nanocomposite fibers were examined using a scanning electron microscope (SEM, Stereoscan 440, UK) and each SEM micrograph was analysed using an image tool (UTHSCSA Image Tool). Apart from using SEM, the presence of CHA nanoparticles in the nanocomposite fibers was studied using the spot analysis of energy-dispersive X-ray spectroscopy (EDX) and the distribution of these nanoparticles was evaluated using EDX mapping. Hereafter, CHA/PHBV nanocomposite fibrous membranes fabricated via Route II were used for characterization.

Mechanical evaluation of both electrospun PHBV polymer fibrous membranes and CHA/PHBV nanocomposite fibrous membranes was performed by tensile tests. The preparation of samples and tensile testing were partly based on an ASTM standard (ASTM C1557). Briefly, hollow rectangular paper frames (outer dimension: $45 \times 25 \mathrm{~mm}$; inner dimension: $20 \times 15 \mathrm{~mm}$ ) were prepared. Electrospun fibrous membranes were cut into $30 \times 5 \mathrm{~mm}$ strips and each strip was mounted onto a paper frame which supported the fibrous sample between the upper and lower rows of the frame over the window in the frame center. The whole assembly of paper frame and fibrous strip was then inserted into the jaws of a testing machine with a gauge length of $20 \mathrm{~mm}$. The side columns of the paper frame were cut before the tensile test started. The thickness of each fibrous membrane was measured using a digital micrometer (Mitutoyo, Japan). The fibrous membranes were pulled monotonically at a rate of $2 \mathrm{~mm} / \mathrm{min}$ to the point of tensile failure using a tabletop Instron tester (Model 5848) with a load cell of $10 \mathrm{~N}$. The ultimate tensile strength, Young's modulus and elongation at break were determined from the tensile stress/strain curves constructed by the machine-recorded data. The values of these properties were expressed as the mean \pm standard deviation. 
The wettability of the PHBV polymer fibrous membranes and CHA/PHBV nanocomposite fibrous membranes was studied using a contact angle measuring machine (SL200B, Shanghai Solon Tech Inc Ltd, China). The contact angles of PHBV solvent-cast films were also determined. The sessile drop method was employed, with distilled water as liquid. The specimen was first attached onto the holder of the contact angle measuring machine. A $1 \mathrm{~mL}$ syringe connected to a $0.5 \mathrm{~mm}$ inner diameter needle was used to supply a water drop of $0.4 \mu \mathrm{L}$ at each measure. The contact angle of the water drop on the specimen surface was determined at room temperature following a standardized procedure and using a proprietary software. Three measurements were carried out at different locations of the same specimen and the average value was obtained. The contact angle was expressed as the mean \pm standard deviation. Fourier transform infrared (FTIR) spectroscopic analysis of electrospun PHBV polymer fibrous membranes and CHA/PHBV nanocomposite fibrous membranes were conducted using an FTIR equipment (Spectrum BX FTIR spectrometer from Perkin-Elmer, USA) over a range of $600-4000 \mathrm{~cm}^{-1}$ at a resolution of $2 \mathrm{~cm}^{-1}$.

\subsection{Biological evaluation}

\subsubsection{Cell culture with SaOS-2 osteoblastic cells}

Human osteoblast cells (SaOS-2) were used to investigate the cell behaviour on both types of electrospun fibrous membranes, namely, PHBV polymer fibrous membranes and CHA/PHBV nanocomposite fibrous membranes. CHA/PHBV nanocomposite fibrous membranes produced through Route II were used for in vitro biological evaluation. SaOS-2 cells were cultured in Dulbecco's Modified Eagle Medium (DMEM) containing $10 \%(\mathrm{v} / \mathrm{v})$ fetal bovine serum $(\mathrm{FBS})$ at $37^{\circ} \mathrm{C}$ in a $5 \%(\mathrm{v} / \mathrm{v}) \mathrm{CO}_{2}$ incubator. The medium was replaced once every 2 days and the cultures were maintained in the same conditions. When the cells reached $80 \%$ confluence, they were trypsinized with $0.25 \%(\mathrm{w} / \mathrm{v})$ trypsin-ethylenediaminetetraacetic acid (trypsin-EDTA) (Invitrogen Co., USA) and counted by a haemocytometer (Tiefe Depth Profondeur, Marienfeld, Germany) prior to being used in the experiments. SaOS-2 cells were seeded onto each type of 
the fibrous membranes and assessments were made on their morphology, proliferation and alkaline phosphatase (ALP) activity at different time points: 2, 7 and 14 days.

\subsubsection{Assessment of cell proliferation}

The SaOS-2 proliferation on PHBV polymer fibrous membranes and CHA/PHBV nanocomposite fibrous membranes were assessed at different time points. Each fibrous membrane was cut into a square shape with a dimension of $5 \times 5 \mathrm{~mm}$. The membranes were then sterilized by Gamma ray at a dosage of $30 \mathrm{kGy}$ before cell culture. The sterilized membranes were attached onto the bottom of the wells of 48-well plates by autoclaved glass rings. SaOS-2 cells were then seeded onto each membrane at $1 \times 10^{5}$ cells $/$ well. After 24 hours, DMEM was removed and the membrane was washed with phosphate buffered saline (PBS) twice to remove non-adhering cells. Culture of adhered SaOS-2 cells continued for 2, 7 and 14 days. DMEM was renewed every 2 days during the whole cell culture period. At the end of each time point, the absorbance was determined by 3-(4,5-dimethylthiazol-2-yl)-2,5-diphenyltetrazolium bromide (MTT) assay. Three fibrous membranes were used for each type of membranes at every time point while the differences between different types of fibrous membranes were evaluated using the student's $t$-test, with $p$-value $<0.05$ being significant.

\subsubsection{Assessment of ALP activity of cells}

The fibrous membranes for ALP activity assessment were prepared as described in Section 2.3.2. After sterilization by Gamma ray at a dosage of $30 \mathrm{kGy}$, SaOS-2 cells were seeded onto each membrane at $1 \times 10^{5}$ cells/well and DMEM was replenished every 2 days until the end of each time point $(2,7$ and 14 days). ALP activity expressed by the SaOS-2 cells seeded on each type of fibrous membranes was assessed at each time point. First, each membrane was rinsed twice with PBS to remove non-adhering cells. Then the membrane was incubated in trypsin-EDTA for 3 minutes to detach the cells. After adding DMEM to stop the reaction, the cell suspension was centrifuged at $3000 \mathrm{rpm}$ for 5 minutes and the obtained cells were mixed with lysis buffer containing $0.1 \%(\mathrm{v} / \mathrm{v})$ Triton $\mathrm{X}-100,1 \mathrm{mM} \mathrm{MgCl}$, and 20 
$\mathrm{mM}$ tris(hydroxymethyl)aminomethane (Tris). Two cycles of freezing and thawing followed to disrupt the cell membranes. ALP activities of the cells were assessed by measuring the release of $p$-nitrophenol (pNP) from $p$-nitrophenylphosphate (pNPP). Briefly, the cell suspension was reacted with the ALP substrate solution containing pNPP (Sigma, USA) at $37^{\circ} \mathrm{C}$ for 30 minutes. Addition of $3 \mathrm{~N} \mathrm{NaOH}$ ended the reaction. The ALPase, a measure of ALP activity, reacted with pNPP to give pNP, which was measured by a microplate reader at a wavelength of $405 \mathrm{~nm}$. The amount of protein in the cell suspension was found by Bicinchoninic acid (BCA) assay kit (Pierce, Rockford, IL) with bovine serum albumin as a standard. The ALP activity expressed by the SaOS-2 cells seeded on each type of fibrous membranes was expressed as $\mu \mathrm{mol}$ of $\mathrm{pNP}$ formation per milligram of protein per hour ( $\mu \mathrm{mol} / \mathrm{mg}$ protein $/ \mathrm{hr})$. Again, three membranes were used for each type of membranes at every time point while the differences between different types of fibrous membranes were evaluated using the student's $t$-test, with $p$-value $<0.05$ being significant.

\subsubsection{Assessment of cell morphology on fibrous membranes}

SaOS-2 cells were seeded at $1 \times 10^{5}$ cells/well onto both types of fibrous membranes (PHBV and CHA/PHBV), as described in Sections 2.3.2 and 2.3.3. The cell morphologies on each fiber type were examined by SEM at different time points (2, 7 and 14 days). At each time point, DMEM was removed and the membrane samples were washed with PBS twice to remove non-adhering cells. SaOS-2 cells on membranes were then fixed in $2.5 \%$ glutaraldehyde in cacodylate buffer $(0.1 \mathrm{M}$ sodium cacodylate- $\mathrm{HCl}$ buffer, $\mathrm{pH} 7.4$ ) at $4^{\circ} \mathrm{C}$ for 24 hours. The membranes with fixed cells were washed with cacodylate buffer with $0.1 \mathrm{M}$ sucrose to remove the remaining glutaraldehyde. After dehydration of the membranes with cells in an up-grading series of ethanol (30,50, 70, 90 and $100 \%)$, the membranes were dried in a Critical Point Dryer (BAL-TEC CPD 030, Liechtenstein) using liquid carbon dioxide as transitional fluid. Finally, the fibrous membranes with cells were sputter-coated with a thin gold layer and examined under SEM.

\section{Results and discussion}




\subsection{Comparison of three routes for fabricating nanocomposite fibers}

Electrospun PHBV fibers without CHA are shown in figure 2. The average fiber diameter was $3.53 \mu \mathrm{m}$ (from 2.75 to $5.22 \mu \mathrm{m}$, S.D. $=0.48 \mu \mathrm{m}$ ) and the fiber surface was smooth. The CHA nanoparticles used for making CHA/PHBV nanocomposite fibrous membranes in this study were spherical in shape, with diameters of 10-30 nm (figure 3). As is described in Section 2.1, the CHA/PHBV nanocomposite fibrous membranes were fabricated by electrospinning via three routes. It was found that Route I could produce CHA/PHBV nanocomposite fibrous membranes with CHA content up to $15 \mathrm{wt} \%$. Figure 4 shows the nanocomposite fibers electrospun through Route I. The distribution of CHA nanoparticles was not homogeneous and agglomerated CHA clusters were frequently observed. The needle was easily blocked during electrospinning when the CHA content was greater than $10 \mathrm{wt} . \%$, resulting in insufficient fiber formation. Route II allowed the formation of nanocomposite fibers with CHA content also up to 15 wt.\%. Figure 5 diaplays the SEM micrographs and the corresponding EDX mapping of the CHA/PHBV nanocomposite fibers fabricated through Route II. Compared with the Route I, the CHA nanoparticles distribution was relatively homogeneous. Figure $5(B)$ shows the electrospun CHA/PHBV nanocomposite fibers with CHA content of 10 wt.\%. The presence of CHA is represented by the white dots, which suggests that CHA nanoparticles were evenly distributed over the whole fibrous membrane. CHA was found in limited regions only when its content was 5 wt.\% (figure 5(A)) while some particle agglomeration occurred when its content became 15 wt.\% (figure 5(C)). Route III caused rapid evaporation of the solvent and hence quick solidification of the polymer solution during electrospinning, which ended the electrospinning process within a very short period of time.

It is believed that in Route I, agglomeration of CHA nanoparticles occurred immediately after mixing the nanoparticles with the PHBV solution. CHA nanoparticles may have been poorly dispersed and they easily agglomerated during the traditional electrospinning process (figure $1(A)$ ), resulting in the uneven distribution of the CHA nanoparticles within the electrospun fibers (figure $4(C)$ ). On the contrary, the distribution of the white dots in figure $5(B)$ indicates that the CHA nanoparticles were distributed around 
the whole fibrous membrane rather than agglomerated into limited area. In this route (i.e. Route II, figure $1(B)$ ), ultrasonic power was applied to the CHA/PHBV solution during the solution preparation process so that the CHA nanoparticles were dispersed in the polymer solution. The polymer solution containing dispersed CHA nanoparticles was immediately used for electrospinning, resulting in the formation of nanocomposite fibers with reasonably homogeneous distribution of CHA nanoparticles. As the formation of CHA/PHBV nanocomposite fibrous membranes in this route did not involve the use of any dispersant and CHA nanoparticles were dispersed in composite fibers reasonably well, the nanocomposite fibrous membrane formed could be very useful for bone tissue engineering. Nevertheless, some CHA nanoparticles still agglomerated, as shown in figure 5(C), when the CHA content of the nanocomposite fibrous membrane became $15 \mathrm{wt} . \%$. This is because there was a time gap between the solution preparation process and the fiber formation process. Although CHA nanoparticles were dispersed effectively during the solution preparation process, agglomeration could still occur during the electrospinning process no matter how quickly the electrospinning process took place after the solution preparation process. To eliminate the time gap between these two processes, Route III (figure 1(C)) was investigated. As the ultrasonic power was applied continuously during the electrospinning process, CHA nanoparticle agglomeration should not occur. However, the rapid evaporation of solvent from the polymer solution which contained CHA nanoparticles in Route III totally undermined electrospinning of nanocomposite fibers. Therefore, it appears that Route II is the only promising approach for fabricating usable nanocomposite fibrous membranes among these three routes.

\subsection{Morphology of nanocomposite fibers}

Generally, for relatively small amounts of nanoparticles, the CHA nanoparticles can be incorporated into the electrospun fibers in three different ways and the way of incorporation depends on the relative size of electrospun fibers. If the diameter of the electrospun fiber is significantly smaller than that of CHA nanoparticle, the nanoparticles tend to attach to the surface of the fiber, as shown in figure $6(A)$. If diameters of both the fiber and nanoparticles are similar, the nanoparticles can be partially encapsulated 
(figure $6(B)$ ). If the diameter of the fiber becomes significantly larger than that of nanoparticles, the nanoparticles can be totally encapsulated (figure $6(C)$ ). When the amount of CHA nanoparticles to be contained in the nanocomposite fibers exceeds a critical CHA volume fraction for the fibers, fibers as schematically presented in figure 7 may be obtained. Complete encapsulation of CHA nanoparticles may be good for mechanical property of the fiber while partial encapsulation or nanoparticle attachment to fiber surface is good for bioactivity of the fiber. Since PHBV is biodegradable, the desirable properties of the CHA nanoparticles can still be utilized during fiber degradation when the nanoparticles become exposed, even though they may be totally encapsulated at the beginning of implantation. Figure 8 shows high magnification SEM micrographs and corresponding EDX spectra of the CHA/PHBV nanocomposite fibers. Figure $8(A)$ illustrates a complete encapsulation of the CHA nanoparticles in the CHA/PHBV nanocomposite fibers while figure $8(B)$ shows an attachment of the CHA nanoparticles on the CHA/PHBV nanocomposite fibers. The Ca and P peaks in the EDX spectra confirmed the presence of CHA in these CHA/PHBV nanocomposite fibers. Table 1 provides the results obtained from the EDX analysis of electrospun CHA/PHBV nanocomposite fibrous membranes having encapsulated CHA nanoparticles in the fibers (i.e. the fibers shown in figure $8(A)$ ) and attached CHA nanoparticles on the fibers (i.e. the fibers shown in figure $8(B)$ ). The latter rendered higher contents of $\mathrm{Ca}$ and $\mathrm{P}$ than the former, thus confirming the SEM observations.

\subsection{Tensile properties of PHBV and CHA/PHBV fibrous membranes}

The thickness of the PHBV or the CHA/PHBV fibrous membrane was around $100 \mu \mathrm{m}$. Figure 9 shows the tensile curves of the electrospun PHBV and CHA/PHBV nanocomposite fibrous membranes. As shown in table 2, the average ultimate tensile strength of the PHBV polymer fibrous membranes was comparable to that of the CHA/PHBV nanocomposite fibrous membranes. Table 2 also shows that the average Young's modulus of PHBV polymer fibrous membranes was comparable to that of the CHA/PHBV nanocomposite fibrous membranes. However, the average ultimate strain of CHA/PHBV nanocomposite fibrous membranes was significantly lower than that of PHBV polymer fibrous 
membranes. These results showed that incorporation of CHA nanoparticles would not significantly influence the ultimate tensile strength and stiffness of the PHBV fibrous membranes but significantly reduce the ultimate strain of the membranes. As there was no chemical bonding between CHA nanoparticles and PHBV matrix and the mechanical bonding between them was weak, the CHA incorporated fibrous membranes exhibited decreased ductility through debonding and void coalescence in nanocomposite fibers. Interfacial debonding occurred between CHA nanoparticles and PHBV matrix during tensile testing, which led to fracture of nanocomposite fibers. Nevertheless, both types of fibrous membranes offer sufficient mechanical properties for non-load bearing applications.

\subsection{Wettability of PHBV and CHA/PHBV fibrous membranes}

The wettabilities of solvent-cast PHBV films, electrospun PHBV polymer fibrous membranes and electrospun $\mathrm{CHA} / \mathrm{PHBV}$ nanocomposite fibrous membranes were determined by water contact angle measurement, and the results are summarized in table 3. It can be seen from table 3 that electrospun PHBV polymer fibrous membranes were hydrophobic, as indicated by their high water contact angles. The average water contact angle of electrospun PHBV polymer fibrous membranes was significantly higher than that of solvent-cast PHBV films because the surface roughness of the fibrous membranes was higher than that of the films. The water droplet could not easily penetrate into the inter-fiber pores on the rough surface of the hydrophobic fibrous membranes. The water droplet was merely supported on a semisolid and semi-air plane surface, resulting in a significant increase in the water contact angle. A similar observation was made by Ma and co-workers who found that the water contact angle of electrospun polyethylene terephthalate (PET) fibrous membrane was significantly larger than that of the PET film [22]. It can also be seen from table 3 that electrospun CHA/PHBV nanocomposite fibrous membranes exhibited zero water contact angle, indicating that incorporation of CHA nanoparticles significantly increased the wettability of electrospun PHBV polymer fibrous membranes. In a study about electrospinning of nanocomposite fibers, Xu et al. reported that incorporation of HA nanoparticles would not significantly affect the contact angle when most of the nanoparticles were encapsulated in the fibers 
but the effect was prominent when many nanoparticles were located on the fiber surfaces [23]. In the present study, the CHA nanoparticles were not only encapsulated in the fibers but also attached on the fibers, leading to the formation of a rough and relative hydrophilic surface for CHA/PHBV nanocomposite fibrous membranes. As cells tend to attach and spread on hydrophilic surfaces rather than hydrophobic surfaces [24-27], the effectiveness of incorporated CHA nanoparticles in improving the wettability of electrospun fibrous membranes indicates that the electrospun CHA/PHBV nanocomposite fibrous membrane can be potentially useful for bone tissue engineering.

\section{5. $\quad$ Fourier transform infrared (FTIR) spectroscopic analysis}

FTIR spectra of PHBV polymer fibrous membrane and CHA/PHBV nanocomposite fibrous membrane are displayed in figure 10. The spectra of both PHBV and CHA/PHBV exhibited several common peaks due to the matrix polymer of PHBV. These absorption peaks were the asymmetric stretching vibration of $\mathrm{C}-\mathrm{CH}_{2}$ at $2918 \mathrm{~cm}^{-1}$, the symmetric stretching vibration of $\mathrm{C}-\mathrm{CH}_{2}$ at $2849 \mathrm{~cm}^{-1}$, the carbonyl peak at 1651

$\mathrm{cm}^{-1}$, the methyl peak at $1379 \mathrm{~cm}^{-1}$, and the stretching vibration of $\mathrm{C}-\mathrm{O}$ at $1219 \mathrm{~cm}^{-1}$. There was a common peak of the asymmetric stretching vibration of $\mathrm{CO}_{2}$ at $2357 \mathrm{~cm}^{-1}$, suggesting that some air was trapped in the fibrous membranes. Apart from the aforementioned common peaks, additional absorption peaks were found in the FTIR spectrum for CHA/PHBV. This spectrum also exhibited peaks for the $\mathrm{OH}^{-}$ group at $3289 \mathrm{~cm}^{-1}$, the $\mathrm{CO}_{3}{ }^{2-}$ group at $1717 \mathrm{~cm}^{-1}$ and $1455 \mathrm{~cm}^{-1}$, as well as the $\mathrm{PO}_{4}{ }^{3-}$ group at $1054 \mathrm{~cm}^{-1}$. The peaks for the $\mathrm{OH}^{-}$group and the $\mathrm{PO}_{4}{ }^{3-}$ group confirmed the existence of $\mathrm{HA}$ in the nanocomposite fibrous membrane while the peak for the $\mathrm{CO}_{3}{ }^{2-}$ group confirmed that the nanoparticles fabricated and used in this study were indeed carbonated HA. Apart from the peaks for PHBV and CHA, no additional peak was found in the FTIR spectrum for CHA/PHBV, indicating that there was no chemical bonding between CHA nanoparticles and PHBV matrix.

\subsection{Cell proliferation}


The proliferation of SaOS-2 cells on both types of electrospun fibrous membranes (i.e. PHBV and $\mathrm{CHA} / \mathrm{PHBV}$ ) as well as on the tissue-culture polystyrene plate (i.e. the control) in terms of the relative absorbance is shown in figure 11. The absorbance for each type of fibrous membranes was comparable to that for the control at every time point. The absorbance of PHBV polymer and CHA/PHBV nanocomposite fibrous membranes generally increased from day 2 to day $7(p<0.05)$ but did not change significantly from day 7 to day 14 . Ideally, compared with the PHBV polymer fibrous membranes without CHA, the CHA nanoparticles should chemically and structurally mimic the mineral portion of bone and hence the CHA/PHBV nanocomposite fibrous membranes should elicit a higher proliferation rate of osteoblasts. However, according to the current study, there was no significant difference in the number of proliferated cells between PHBV polymer and CHA/PHBV nanocomposite fibrous membranes at every time point. This may be explained from the morphological point of view. As both PHBV and CHA/PHBV fibers had similar fiber diameters of about $3 \mu \mathrm{m}$, they should provide similar specific surface areas (SSA) for cell attachment and proliferation. The effects of fiber diameter and SSA on cell attachment were investigated by Chen et al., who demonstrated that small fiber diameter and large SSA improved cell attachment at sufficiently high serum concentrations [28]. Other studies also revealed the morphological impact on cell attachment and proliferation [29, 30]. Since the fiber morphology (including fiber diameter and SSA) is the primary factor for influencing cell attachment and proliferation but both PHBV and CHA/PHBV fibers possessed similar morphology, the SaOS-2 cells tended to attach and proliferate on both types of fibrous membranes in the same manner. It was observed that after the rapid proliferation from day 2 to day 7 , the number of proliferated cells on both types of fibrous membranes did not change significantly. It is known that cellular proliferation decreases when cells differentiate into mature, ECM-producing cells [31]. It therefore appeared that SaOS-2 cells may have started the process of differentiation just like other osteoblastic cells naturally do. This cellular event was beneficial because it allowed for the production of critical ECM proteins, leading to bone tissue formation.

\subsection{ALP activity}


ALP is an enzyme secreted by osteoblastic cells for the occurrence of mineralization. Production of ALP is therefore one of the important indicators to confirm the osteoblastic phenotype of SaOS-2 cells on fibrous membranes. The ALP activities of SaOS-2 cells on both types of fibrous membranes (PHBV and $\mathrm{CHA} / \mathrm{PHBV}$ ) and tissue-culture polystyrene plate were evaluated in terms of $\mu \mathrm{mol}$ of $\mathrm{pNP}$ production per milligram of protein per hour on days 2, 7 and 14 of cell culture (figure 12). The ALP activity of SaOS-2 cells seeded on each type of fibrous membranes was also comparable to that on the control on days 2 and 7. On day 14, the ALP activities expressed by cells on the PHBV polymer fibrous membranes were comparable to that on the control while the ALP activity expressed by the cells on CHA/PHBV nanocomposite fibrous membrane was significantly higher than those on PHBV polymer fibrous membranes and the control $(p<0.05)$. The in vitro cell culture results showed that the ALP activity slightly increased from day 2 to day 7 and significantly increased between day 7 and day $14(p<0.05)$. These results indicate that both types of fibrous membranes investigated supported the expression of homogeneous phenotype of SaOS-2 cells throughout the cell culture period of 14 days. High ALP activity of SaOS-2 cells seeded on the CHA/PHBV nanocomposite fibrous membrane was observed on day 14 , which suggested that the presence of CHA nanoparticles in electrospun CHA/PHBV nanocomposite fibers was particularly useful for the expression of ALP activity. As ALP production is one of the steps within the whole differentiation sequence of bone cells, significant ALP expressed by SaOS-2 cells seeded on the nanocomposite fibrous membranes was a clear indication that the nanocomposite fibrous membranes are a suitable candidate for bone tissue engineering applications.

\subsection{Cell morphology}

SaOS-2 cells on both types of fibrous membranes (PHBV and CHA/PHBV) were examined using SEM. Figure 13 displays SEM micrographs of PHBV polymer fibrous membranes seeded with SaOS-2 cells after various cell culture periods (i.e. 2, 7 and 14 days). The PHBV polymer fibrous membranes retained their fibrous architecture throughout the cell culture period, even though they had been immersed in cell culture medium for as long as 14 days. On day 2, cells had already attached to the PHBV polymer fibrous 
membrane and exhibited globular shape with diameters ranging from 5 to $10 \mu \mathrm{m}$ (figure $13(A)$ ). On day 7 , the cells were well expanded and spread in all directions on the fibrous membrane. A majority of cells had diameters over $10 \mu \mathrm{m}$, which were larger than the average diameter of the cells after 2 day cell culture (figure $13(B)$ ). On day 14, the cells not only well expanded and spread but also formed numerous filopodia around the cells (figure 13(C)). With the filopodia, cells could firmly attach to the fibers and migrate on and in fibrous membranes effectively by extending the filopodia. The CHA/PHBV nanocomposite fibrous membranes also allowed cell attachment on day 2, cell spreading on day 7 and induction of filopodia on day 14 (figure 14). Although the number of SaOS-2 cells increased significantly from day 2 to day 7 (figure 11), such an increase could not be easily reflected by the SEM micrographs such as figure 13 and figure 14 because the cells could penetrate into the fibrous membranes through the interstitial pores between the fibers. Figure 15 shows an SaOS-2 cell which partly penetrated into interstitial pores of a PHBV fibrous membrane. As the sizes of interstitial pores were as large as $10 \mu \mathrm{m}$, it was possible for the cells to fully penetrate into the fibrous membrane through these pores. Obviously, SaOS-2 cells having penetrated into fibrous membranes could not be observed under SEM. The penetration of cells into electrospun fibrous structures has also been reported by $\mathrm{Ju}$ et al., who demonstrated that the cells gradually penetrated into the fibrous structures composed of large diameter fibers $(4.45 \mu \mathrm{m}$ in diameter) due to the large pore area of the fibrous structures but failed to penetrate into the fibrous structures composed of small diameter fibers $(<1 \mu \mathrm{m}$ in diameter $)$ due to the small pore area of the fibrous structures [32]. In the present study, the fibrous membranes were mainly composed of microscaled fibers and hence micro-scaled inter-fiber pores, thus leading to the occurrence of cell penetration. The penetration of cells into fibrous membranes is very important for the tissue engineering applications of the electrospun scaffolds. Functional tissue can only be regenerated when cells migrate into the whole scaffolds, not just staying on the scaffold surface. Figure 15 shows promises of electrospun scaffolds for real tissue engineering applications.

\section{Conclusions}


With the aid of ultrasonic power for dispersing CHA nanoparticles in the PHBV solution, through electrospinning, CHA/PHBV nanocomposite fibrous membranes with reasonably homogeneous distribution of CHA nanoparticles were successfully produced without the use of surfactants. Compared with the PHBV polymer fibrous membranes, the CHA/PHBV nanocomposite fibrous membranes exhibited improved wettability while their ultimate tensile strength and stiffness were not significantly affected. Both PHBV polymer fibrous membranes and CHA/PHBV nanocomposite fibrous membranes supported the attachment and proliferation of SaOS-2 cells. Moreover, compared with cells seeded on the PHBV polymer fibrous membranes, SaOS-2 cells seeded on the CHA/PHBV nanocomposite fibrous membranes exhibited higher ALP activity after 14 days of cell culture, indicating better osteoconductivity with the incorporation of CHA nanoparticles in electrospun fibers. The electrospun CHA/PHBV nanocomposite fibrous membrane is a potentially useful scaffold for bone tissue engineering.

\section{Acknowledgements}

This work was supported by a GRF grant (HKU 7176/08E) from the Research Grants Council of Hong Kong. The authors acknowledge the assistance provided by technical staff in the Department of Mechanical Engineering and the Department of Orthopaedics and Traumatology, HKU. 


\section{References}

[1] Ayres C E, Jha B S, Sell S A, Bowlin G L and Simpson D G 2010 Nanotechnology in the design of soft tissue scaffolds: innovations in structure and function Wiley Interdisciplinary Reviews: Nanomedicine and Nanobiotechnology 2 20-34

[2] Nisbet D R, Forsythe J S, Shen W, Finkelstein D I and Horne M K 2009 Review paper: a review of the cellular response on electrospun nanofibers for tissue engineering J. Biomater. Appl. 24 729

[3] Sun J, Wu J, Li H and Chang J 2005 Macroporous poly(3-hydroxybutyrate-co-3-hydroxyvalerate) matrices for cartilage tissue engineering Eur. Polym. J. 41 2443-9

[4] Sombatmankhong K, Sanchavanakit N, Pavasant P and Supaphol P 2007 Bone scaffolds from electrospun fiber mats of poly(3-hydroxybutyrate), poly(3-hydroxybutyrate-co-3hydroxyvalerate) and their blend Polymer 48 1419-27

[5] Yuan J et al. 2010 Fabrication of PHBV/keratin composite nanofibrous mats for biomedical applications Macromol. Res. 17 850-5

[6] Wang M 2003 Developing bioactive composite materials for tissue replacement Biomaterials 24 2133-51

[7] Kim G M, Asran A S, Michler G H, Simon P and Kim J S 2008 Electrospun PVA/HAp nanocomposite nanofibers: biomimetics of mineralized hard tissues at a lower level of complexity Bioinspir. Biomim. 3 046003-1--12

[8] Luong N D, Moon I-S, Lee D S, Lee Y-K and Nam J-D 2008 Surface modification of poly(llactide) electrospun fibers with nanocrystal hydroxyapatite for engineered scaffold applications Mat. Sci. Eng. C-Bio. S. 28 1242-9

[9] Nie H, Beng W S, Fu Y-C and Wang C-H 2008 Three-dimensional fibrous PLGA/HAp composite scaffold for BMP-2 delivery Biotechnol. Bioeng. 99 223-34

[10] Wang L, Feng H-L, Mei F, Hu X-Y, Deng X-L, Yang X-P, Tang J-M and Wang X-Z 2008 Observation of human periodontal ligament cells cultured on electrospun PLLA/HA biomaterial Acta Anatomica Sinica 39 573-7

[11] Zhang Y, Venugopal J R, El-Turki A, Ramakrishna S, Su B and Lim C T 2008 Electrospun biomimetic nanocomposite nanofibers of hydroxyapatite/chitosan for bone tissue engineering Biomaterials 29 4314-22

[12] Gupta D, Venugopal J, Mitra S, Giri Dev V R and Ramakrishna S 2009 Nanostructured biocomposite substrates by electrospinning and electrospraying for the mineralization of osteoblasts Biomaterials 30 2085-94

[13] Guan D, Chen Z, Huang C and Lin Y 2008 Attachment, proliferation and differentiation of BMSCs on gas-jet/electrospun nHAP/PHB fibrous scaffolds Appl. Surf. Sci. 255 324-7 
[14] Asran A S, Henning S and Michler G H 2010 Polyvinyl alcohol-collagen-hydroxyapatite biocomposite nanofibrous scaffold: mimicking the key features of natural bone at the nanoscale level Polymer 51 868-76

[15] Chuenjitkuntaworn B, Supaphol P, Pavasant P and Damrongsri D 2010 Electrospun poly(L-lactic acid)/hydroxyapatite composite fibrous scaffolds for bone tissue engineering Polym. Int. 59 22735

[16] Landi E, Celotti G, Logroscino G and Tampieri A 2003 Carbonated hydroxyapatite as bone substitute J. Eur. Ceram. Soc. 23 2931-7

[17] Liao S, Watari F, Zhu Y, Uo M, Akasaka T, Wang W, Xu G and Cui F 2007 The degradation of the three layered nano-carbonated hydroxyapatite/collagen/PLGA composite membrane in vitro Dent. Mater. 23 1120-8

[18] Zhou W Y, Wang M, Cheung W L, Guo B C and Jia D M 2008 Synthesis of carbonated hydroxyapatite nanospheres through nanoemulsion J. Mater. Sci-Mater. M. 19 103-10

[19] Jose M V, Thomas V, Johnson K T, Dean D R and Nyairo E 2009 Aligned PLGA/HA nanofibrous nanocomposite scaffolds for bone tissue engineering Acta Biomater. 5 305-15

[20] Kim H-W, Lee H-H and Knowles J C 2006 Electrospinning biomedical nanocomposite fibers of hydroxyapaite/ poly(lactic acid) for bone regeneration J. Biomed. Mater. Res. A 79 643-9

[21] Tong H-W and Wang M 2007 Effects of processing parameters on the morphology and size of electrospun PHBV micro- and nano-fibers Key Eng. Mat. 334-335 II 1233-6

[22] Ma Z, Kotaki M, Yong T, He W and Ramakrishna S 2005 Surface engineering of electrospun polyethylene terephthalate (PET) nanofibers towards development of a new material for blood vessel engineering Biomaterials 26 2527-36

[23] Xu X, Chen X, Liu A, Hong Z and Jing X 2007 Electrospun poly(l-lactide)-grafted hydroxyapatite/poly(l-lactide) nanocomposite fibers Eur. Polym. J. 43 3187-96

[24] Bhattarai S R, Bhattarai N, Viswanathamurthi P, Yi H K, Hwang P H and Kim H Y 2006 Hydrophilic nanofibrous structure of polylactide; fabrication and cell affinity J. Biomed. Mater. Res. A 78 247-57

[25] Jia J, Duan Y Y, Yu J and Lu J W 2008 Preparation and immobilization of soluble eggshell membrane protein on the electrospun nanofibers to enhance cell adhesion and growth J. Biomed. Mater. Res. A 86 364-73

[26] Kim C H, Khil M S, Kim H Y, Lee H U and Jahng K Y 2006 An improved hydrophilicity via electrospinning for enhanced cell attachment and proliferation J. Biomed. Mater. Res. B 78 28390

[27] Zhang Y, Ouyang H, Chwee T L, Ramakrishna S and Huang Z-M 2005 Electrospinning of gelatin fibers and gelatin/PCL composite fibrous scaffolds J. Biomed. Mater. Res. B 72 156-65 
[28] Chen M, Patra P K, Lovett M L, Kaplan D L and Bhowmick S 2009 Role of electrospun fibre diameter and corresponding specific surface area (SSA) on cell attachment J. Tissue Eng. Regen. M. 3 269-79

[29] Kwon I K, Kidoaki S and Matsuda T 2005 Electrospun nano- to microfiber fabrics made of biodegradable copolyesters: structural characteristics, mechanical properties and cell adhesion potential Biomaterials 26 3929-39

[30] Christopherson G T, Song H and Mao H-Q 2009 The influence of fiber diameter of electrospun substrates on neural stem cell differentiation and proliferation Biomaterials 30 556-64

[31] Stein G S, Lian J B and Owen T A 1990 Bone cell differentiation: a functionally coupled relationship between expression of cell-growth- and tissue-specific genes Curr. Opin. Cell Biol. 2 1018-27

[32] Ju Y M, Choi J S, Atala A, Yoo J J and Lee S J 2010 Bilayered scaffold for engineering cellularized blood vessels Biomaterials 31 4313-21 


\section{List of Tables}

Table 1 Results of EDX analysis for electrospun CHA/PHBV nanocomposite fibrous membranes

Table 2 Tensile properties of electrospun PHBV polymer and CHA/PHBV nanocomposite fibrous membranes

Table 3 Water contact angles of PHBV solvent-cast film, electrospun PHBV polymer and CHA/PHBV nanocomposite fibrous membranes 
Table 1 Results of EDX analysis for electrospun CHA/PHBV nanocomposite fibrous membranes

\begin{tabular}{lcc}
\hline Sample & Elements & Atomic weight \% \\
\hline Nanocomposite fibrous membrane with complete & $\mathrm{C}$ & 62.62 \\
encapsulation of CHA nanoparticles in CHA/PHBV & $\mathrm{O}$ & 34.40 \\
nanocomposite fibers & $\mathrm{P}$ & 1.08 \\
& $\mathrm{Ca}$ & 1.90 \\
Nanocomposite fibrous membrane with attachment of & $\mathrm{C}$ & 50.40 \\
CHA nanoparticles on CHA/PHBV nanocomposite & $\mathrm{O}$ & 36.24 \\
fibers & $\mathrm{P}$ & 4.90 \\
& $\mathrm{Ca}$ & 8.46 \\
\hline
\end{tabular}


Table 2 Tensile properties of electrospun PHBV polymer and CHA/PHBV nanocomposite fibrous membranes

\begin{tabular}{lccc}
\hline Sample & $\begin{array}{c}\text { Ultimate Tensile Strength } \\
(\mathrm{MPa})\end{array}$ & $\begin{array}{c}\text { Young's Modulus } \\
(\mathrm{MPa})\end{array}$ & $\begin{array}{c}\text { Tensile strain } \\
(\%)\end{array}$ \\
\hline $\begin{array}{l}\text { Electrospun PHBV polymer } \\
\text { fibrous membrane }\end{array}$ & $0.45 \pm 0.02$ & $23.23 \pm 5.27$ & $6.62 \pm 0.21$ \\
$\begin{array}{l}\text { Electrospun CHA/PHBV } \\
\text { nanocomposite fibrous } \\
\text { membrane }\end{array}$ & $0.46 \pm 0.03$ & $24.03 \pm 5.38$ & $4.11 \pm 0.15$ \\
\hline
\end{tabular}


Table 3 Water contact angles of PHBV solvent-cast film, electrospun PHBV polymer and CHA/PHBV nanocomposite fibrous membranes

\begin{tabular}{ll}
\hline Sample & Contact angle $\left(^{\circ}\right)$ \\
\hline PHBV solvent-cast flat film & $68.4 \pm 5.2$ \\
Electrospun PHBV fibrous membrane & $104.2 \pm 3.1$ \\
Electrospun CHA/PHBV nanocomposite fibrous membrane & 0 \\
\hline
\end{tabular}




\section{List of Figures}

Figure 1 Schematic diagrams showing three routes of electrospinning to form $\mathrm{CHA} / \mathrm{PHBV}$ nanocomposite fibers

$(A)$ Route I: traditional mixing

$(B)$ Route II: application of ultrasonic power during solution preparation

(C) Route III: application of ultrasonic power during electrospinning

Figure 2 Electrospun PHBV fibers

(A) low magnification

$(B)$ high magnification

Figure 3 SEM micrograph of CHA nanoparticles synthesized in-house through a nanoemulsion process

Figure 4 CHA/PHBV nanocomposite fibers fabricated via Route I
$(A)$ fibers having $5 \mathrm{wt} . \%$ of $\mathrm{CHA}$
$(B)$ fibers having $10 \mathrm{wt} . \%$ of CHA
(C) fibers having $15 \mathrm{wt} . \%$ of CHA

Figure 5 EDX mapping of CHA/PHBV nanocomposite fibers fabricated via Route II (White dots:

CHA nanoparticles)

(A) fibers having $5 \mathrm{wt} . \%$ of CHA

$(B)$ fibers having $10 \mathrm{wt} . \%$ of CHA

(C) fibers having $15 \mathrm{wt} . \%$ of CHA

Figure 6 Three ways of CHA nanoparticle incorporation in electrospun fibers

$(A)$ attachment of CHA nanoparticles to the surface of the fiber

$(B)$ partial encapsulation of CHA nanoparticles by the fiber

(C) total encapsulation of CHA nanoparticles by the fiber

Figure 7 Partial and total encapsulation of CHA nanoparticles for fibers containing a large amount of CHA nanoparticles

Figure 8 SEM micrograph and the corresponding EDX spectrum obtained from a spot on the fiber

(A) complete encapsulation of CHA nanoparticles in CHA/PHBV nanocomposite fibers

$(B)$ attachment of CHA nanoparticles on CHA/PHBV nanocomposite fibers

Figure 9 Stress-strain curves of the electrospun PHBV polymer and CHA/PHBV nanocomposite fibrous membranes

Figure 10 FTIR spectra of

(A) PHBV fibrous membranes, and

(B) CHA/PHBV nanocomposite fibrous membranes

Figure 11 Proliferation of SaOS-2 cells seeded on both types of fibrous membranes (PHBV and $\mathrm{CHA} / \mathrm{PHBV}$ ) and the control as a function of cell culture time

Figure 12 ALP activity of SaOS-2 cells seeded on both types of fibrous membranes (PHBV and $\mathrm{CHA} / \mathrm{PHBV}$ ) and the control as a function of cell culture time 
Figure 13 Morphology of SaOS-2 cells seeded on fibrous PHBV membranes after various cell culture times (white arrows pointing at filopodia)

(A) 2 days

(B) 7 days

(C) 14 days

Figure 14 Morphology of SaOS-2 cells seeded on fibrous CHA/PHBV nanocomposite membranes after various cell culture times
(A) 2 days
(B) 7 days
(C) 14 days

Figure 15 Penetration of SaOS-2 cell into fibrous PHBV membrane through interstitial pores 
$(A)$

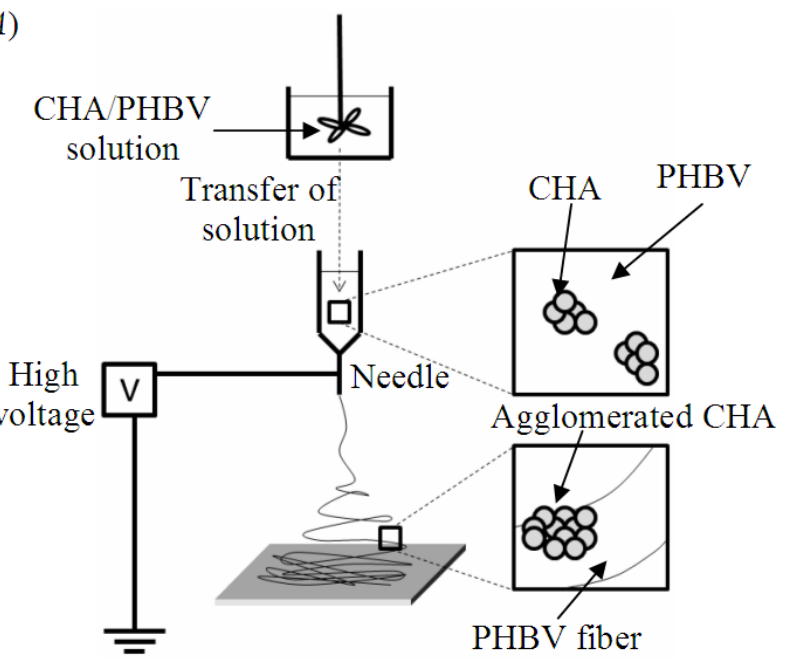

(B)
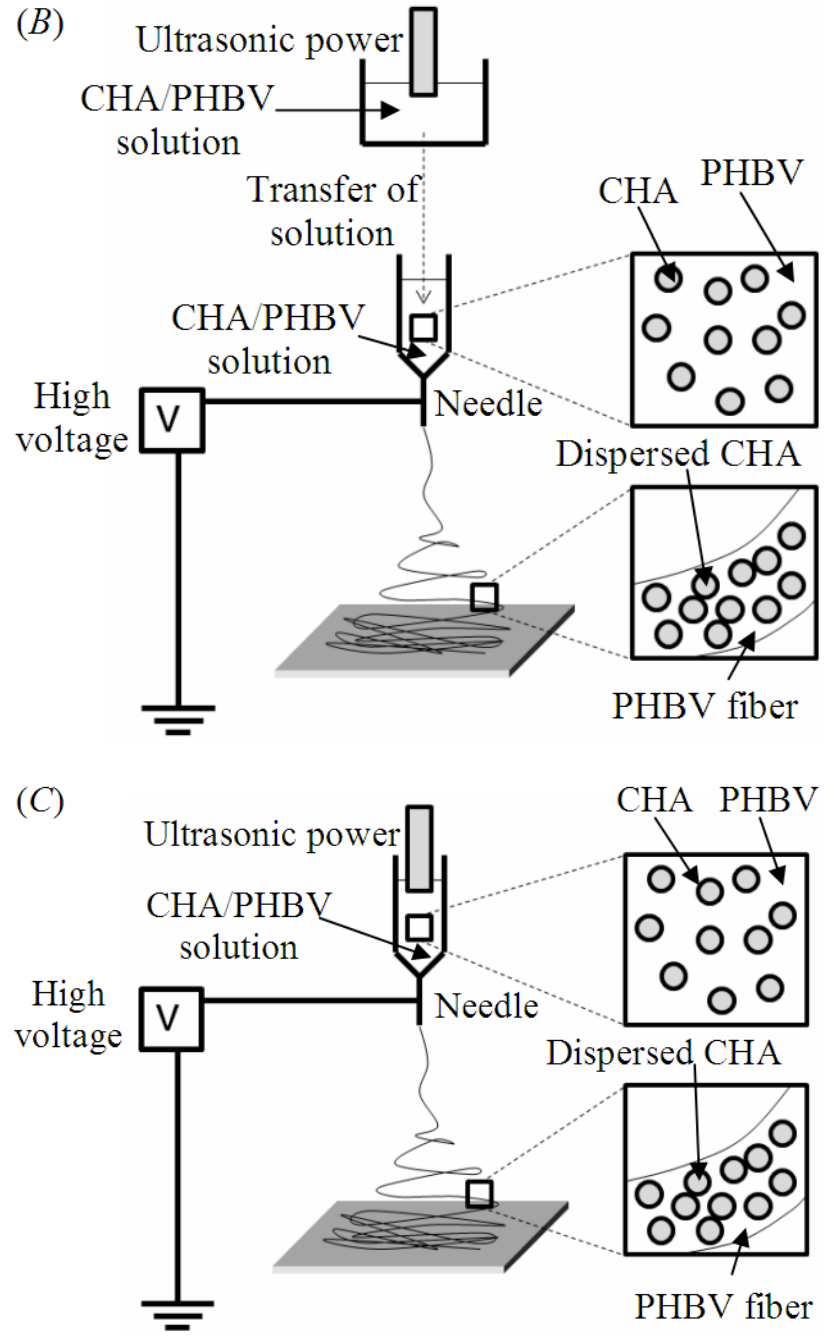

Figure 1. Schematic diagrams showing three routes of electrospinning to form $\mathrm{CHA} / \mathrm{PHBV}$ nanocomposite fibers: $(A)$ Route I: traditional mixing; $(B)$ Route II: application of ultrasonic power during solution preparation; $(C)$ Route III: application of ultrasonic power during electrospinning. 

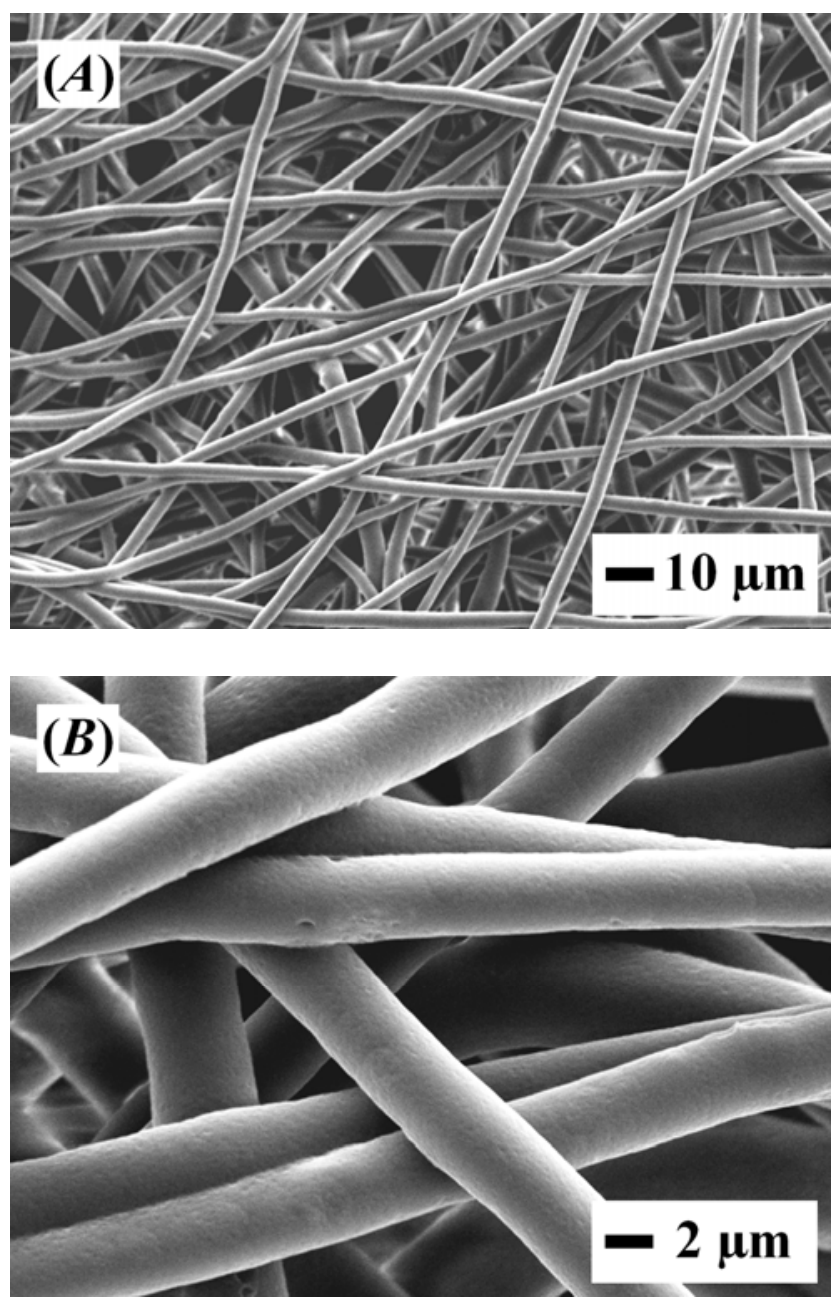

Figure 2. Electrospun PHBV fibers: $(A)$ low magnification; $(B)$ high magnification. 


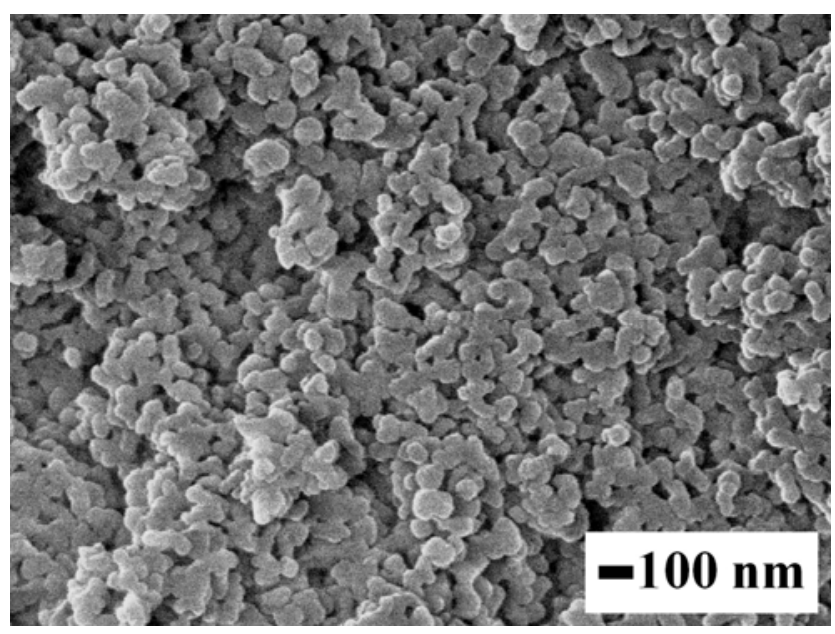

Figure 3. SEM micrograph of CHA nanoparticles synthesized in-house through a nanoemulsion process. 

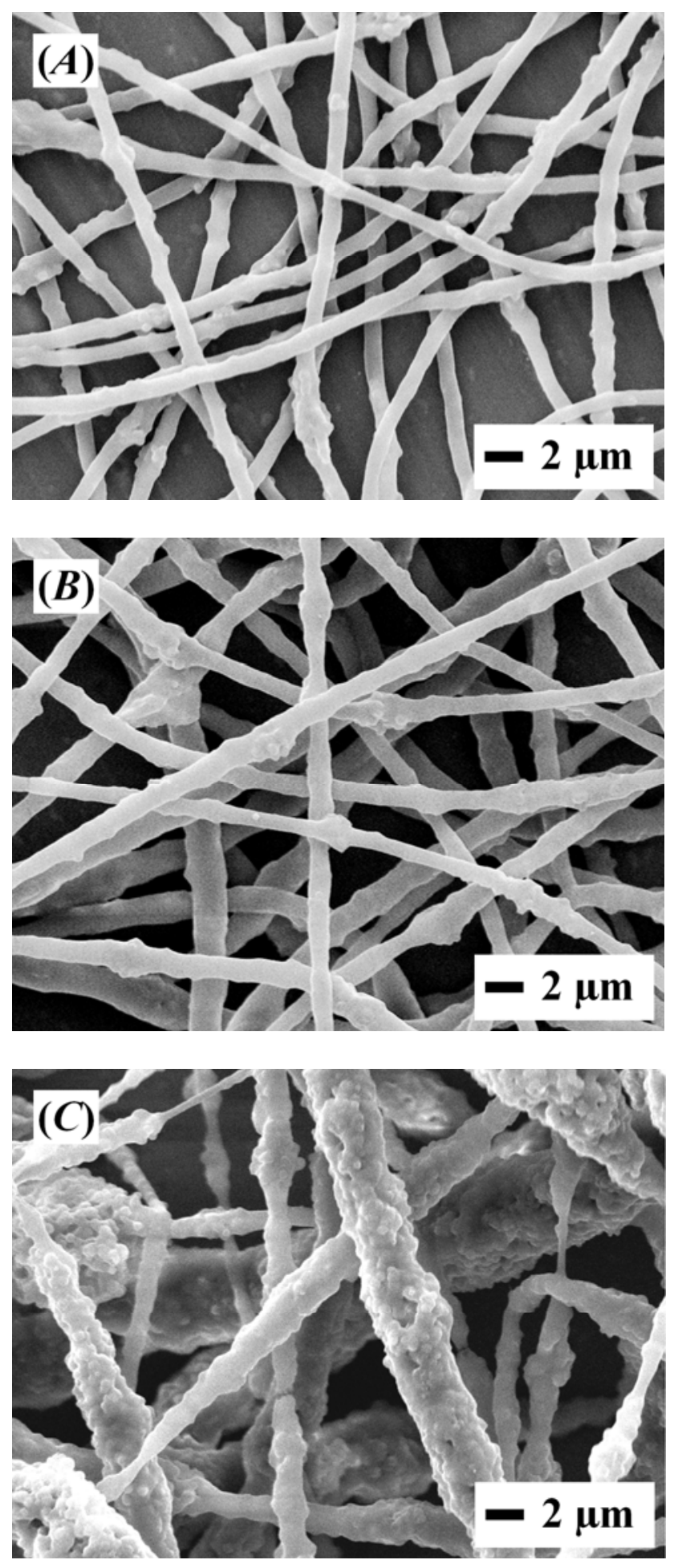

Figure 4. CHA/PHBV nanocomposite fibers fabricated via Route I: $(A)$ fibers having 5 wt.\% of CHA; $(B)$ fibers having $10 \mathrm{wt} . \%$ of CHA; $(C)$ fibers having $15 \mathrm{wt} . \%$ of CHA. 

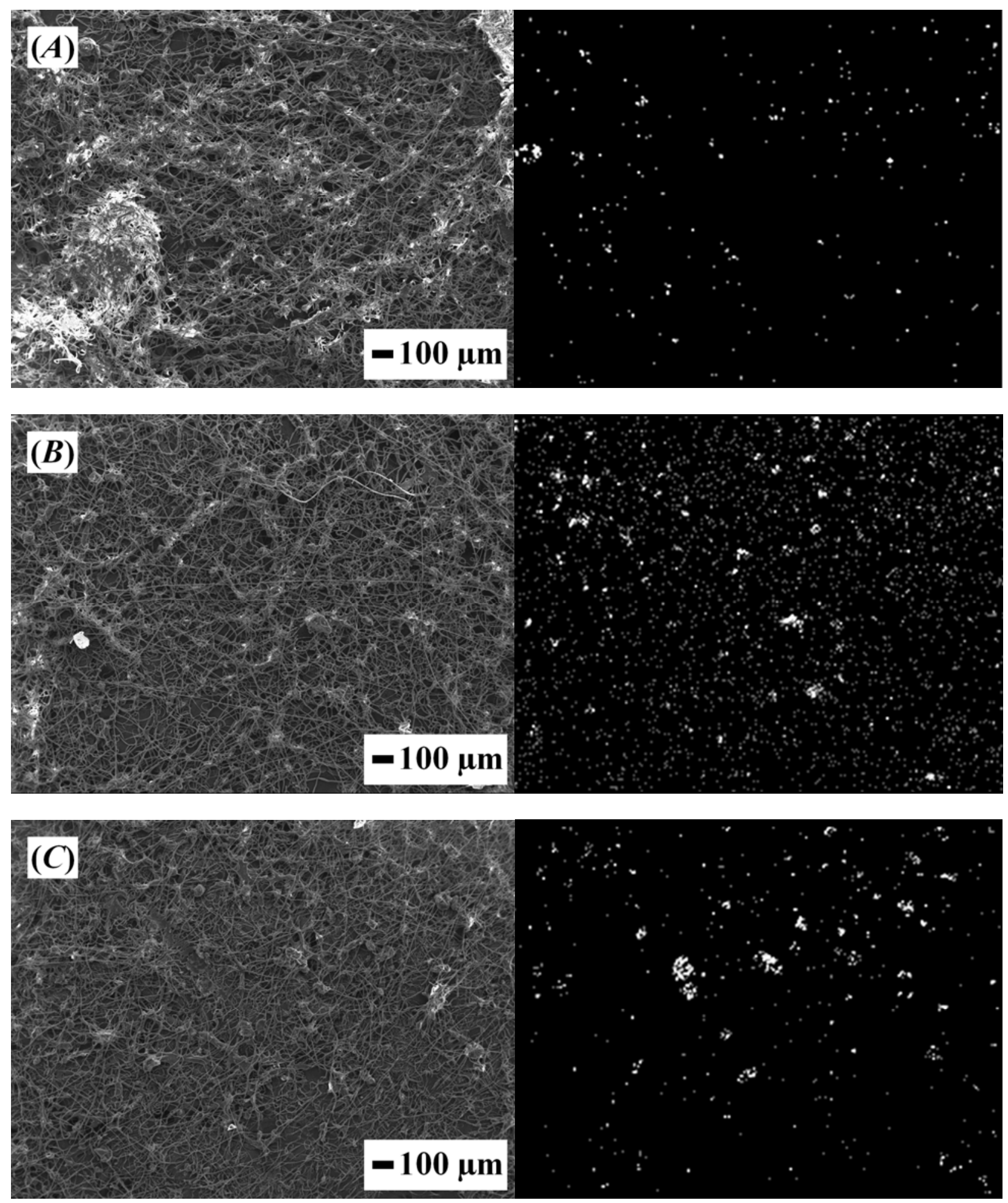

Figure 5. EDX mapping of CHA/PHBV nanocomposite fibers fabricated via Route II (White dots: CHA nanoparticles): $(A)$ fibers having $5 \mathrm{wt} \%$ of $\mathrm{CHA}$; $(B)$ fibers having $10 \mathrm{wt} . \%$ of $\mathrm{CHA}$; $(C)$ fibers having 15 wt. $\%$ of CHA. 
(A)

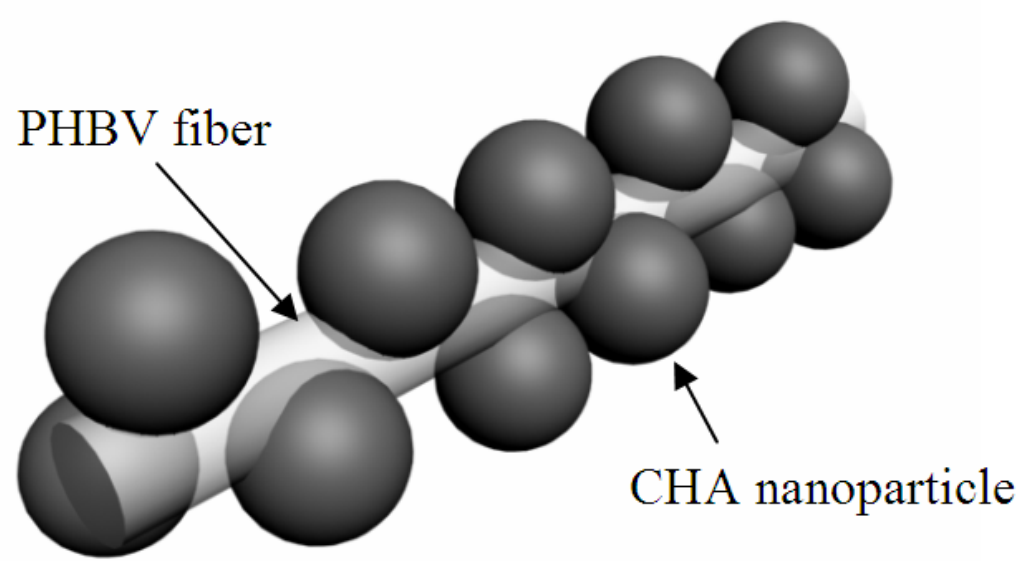

(B)

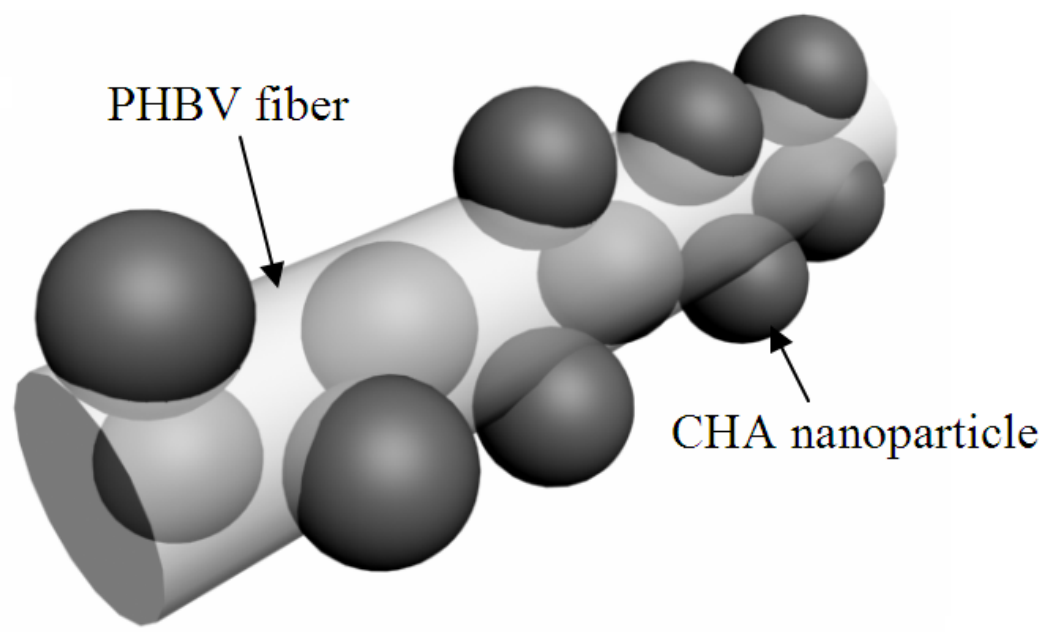

(C)

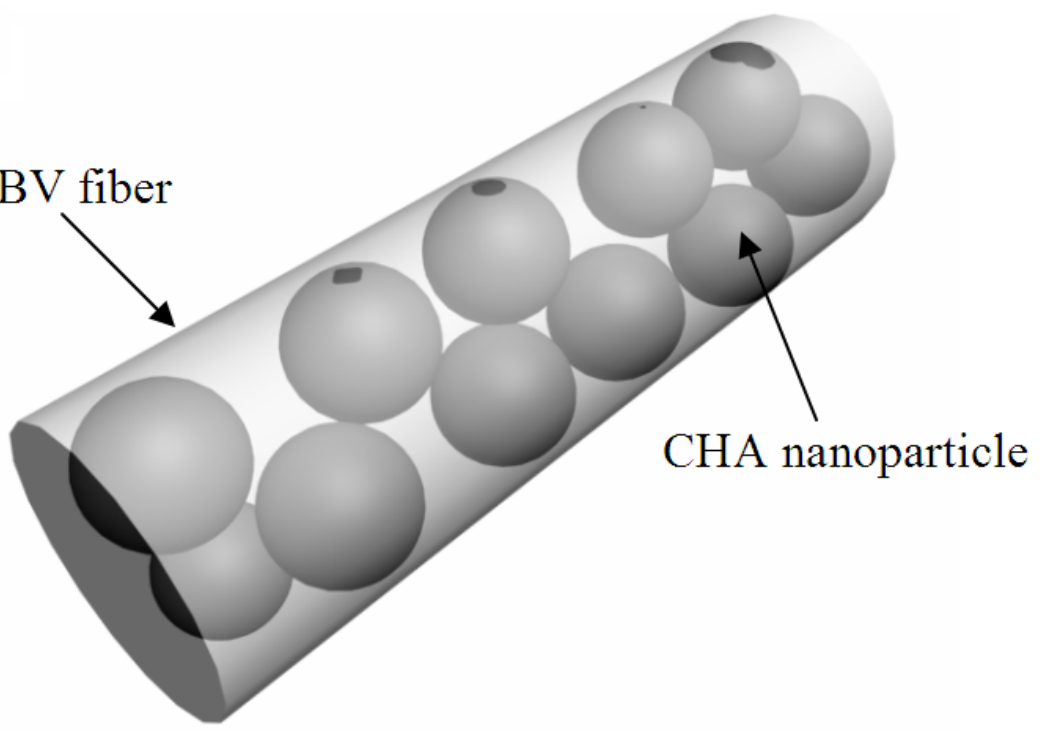

Figure 6. Three ways of CHA nanoparticle incorporation in electrospun fibers: $(A)$ attachment of CHA nanoparticles to the surface of the fiber; $(B)$ partial encapsulation of CHA nanoparticles by the fiber; $(C)$ total encapsulation of CHA nanoparticles by the fiber. 


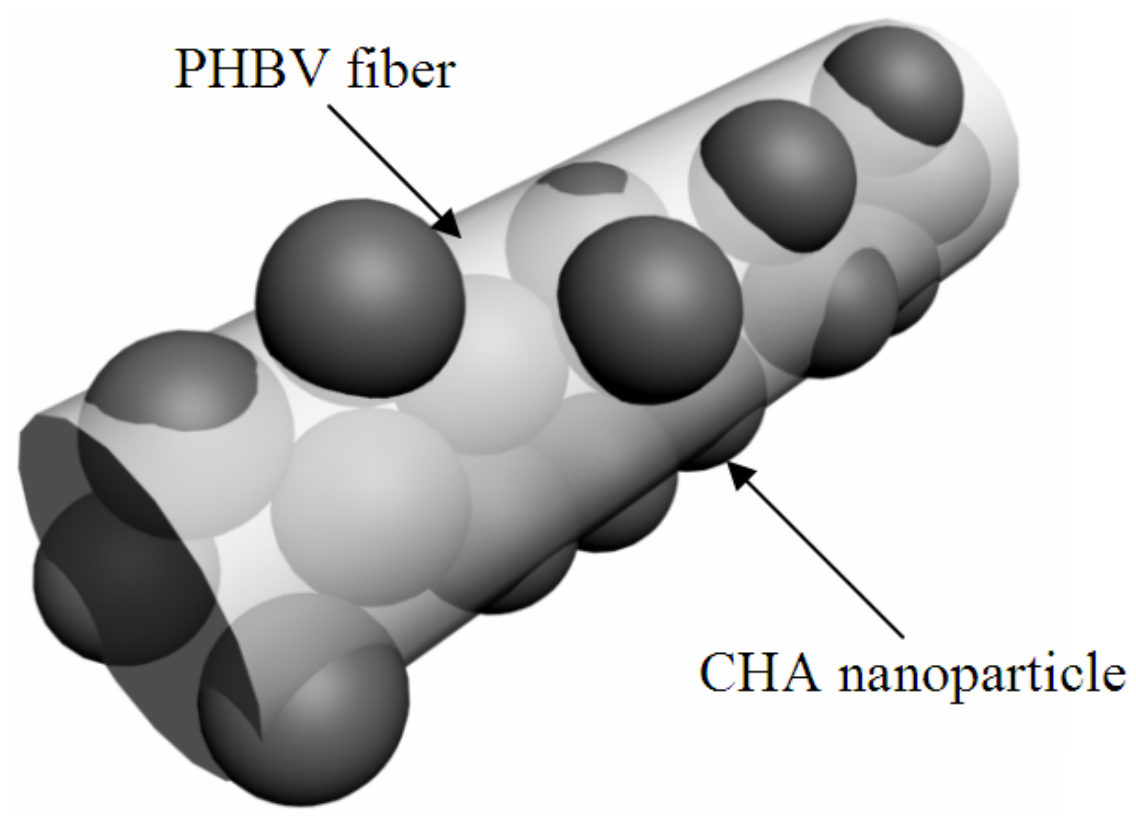

Figure 7. Partial and total encapsulation of CHA nanoparticles for fibers containing a large amount of CHA nanoparticles. 

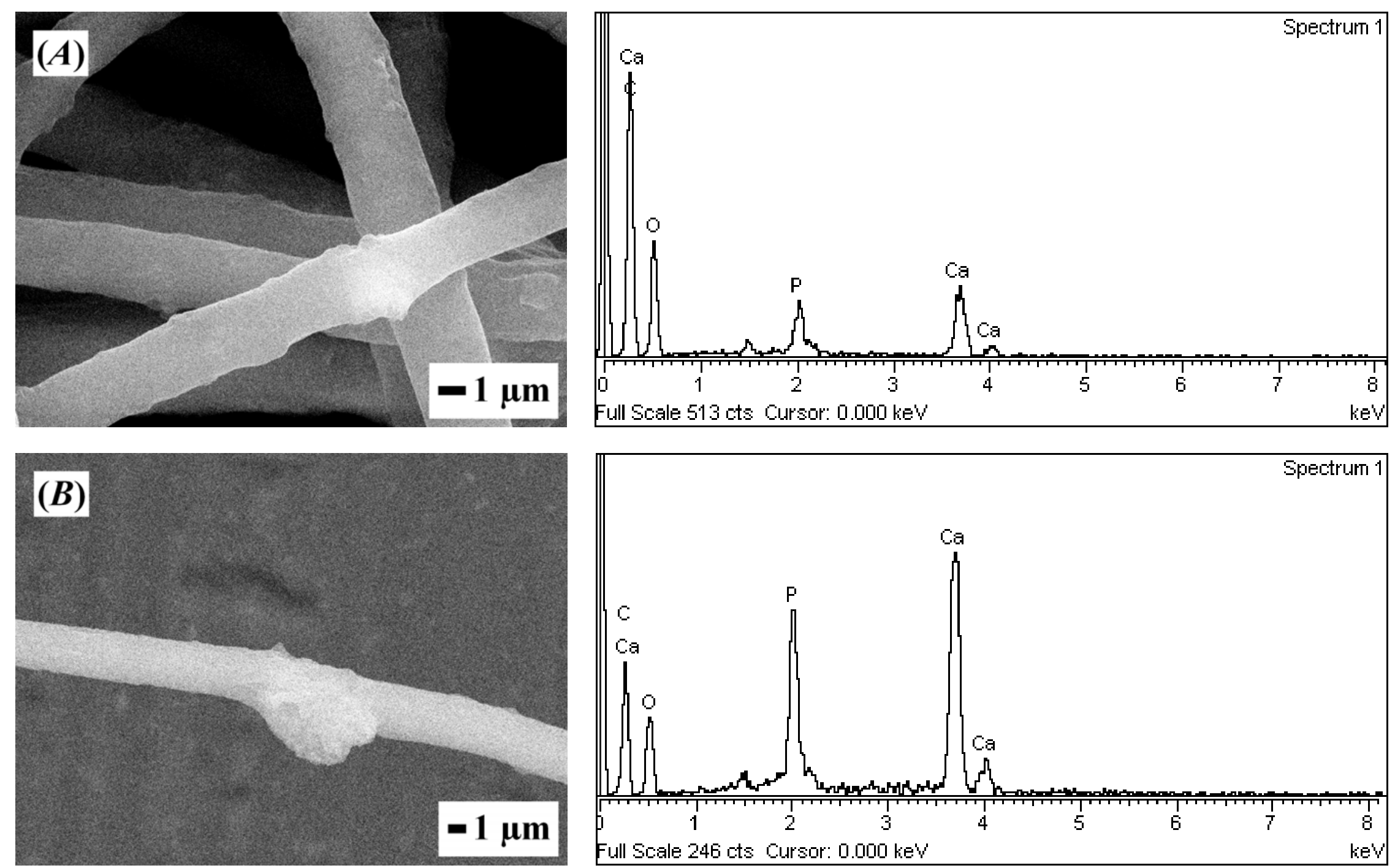

Figure 8. SEM micrograph and the corresponding EDX spectrum obtained from a spot on the fiber: $(A)$ complete encapsulation of CHA nanoparticles in CHA/PHBV nanocomposite fibers; $(B)$ attachment of CHA nanoparticles on CHA/PHBV nanocomposite fibers. 


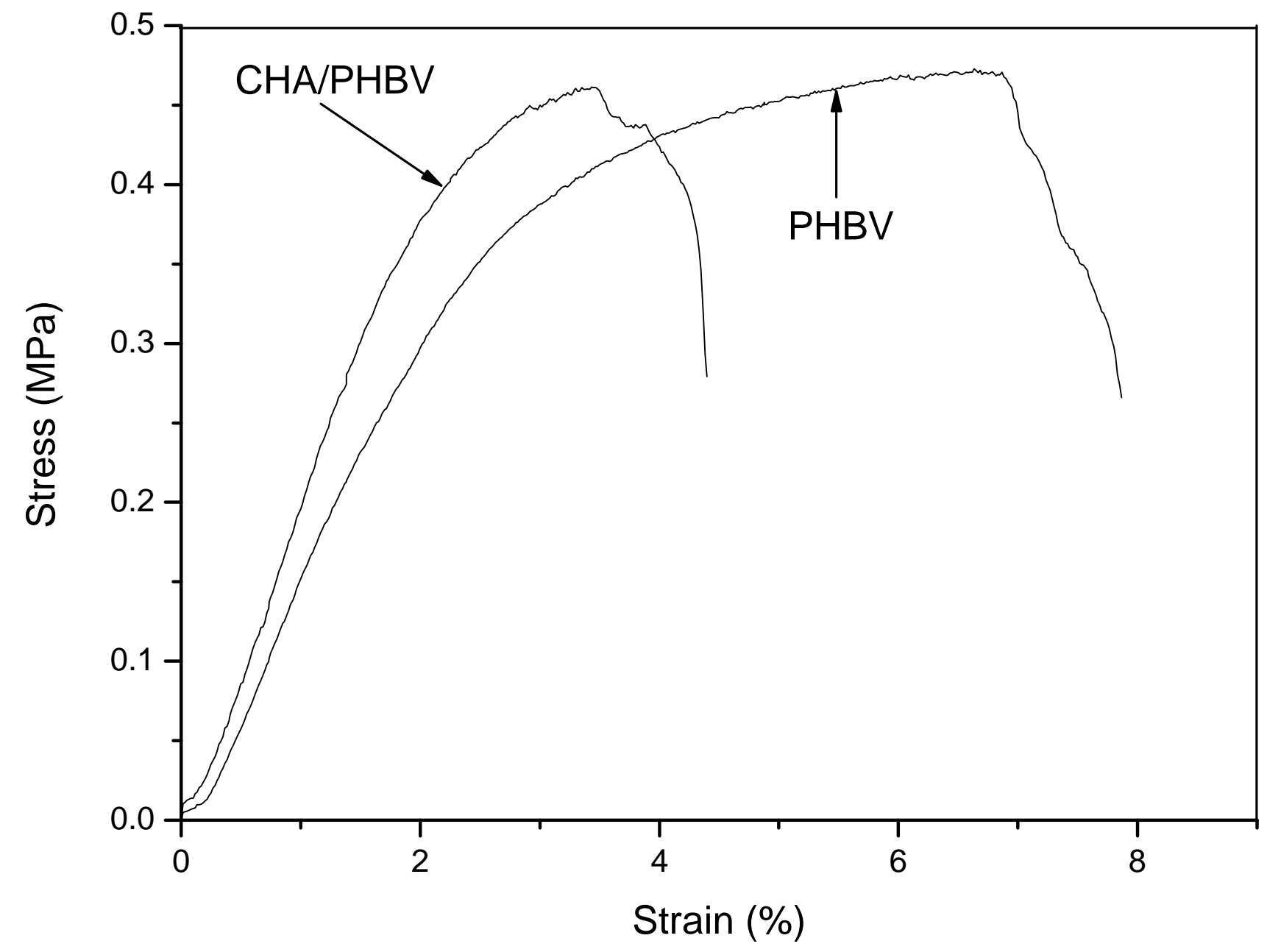

Figure 9. Stress-strain curves of the electrospun PHBV polymer and CHA/PHBV nanocomposite fibrous membranes. 


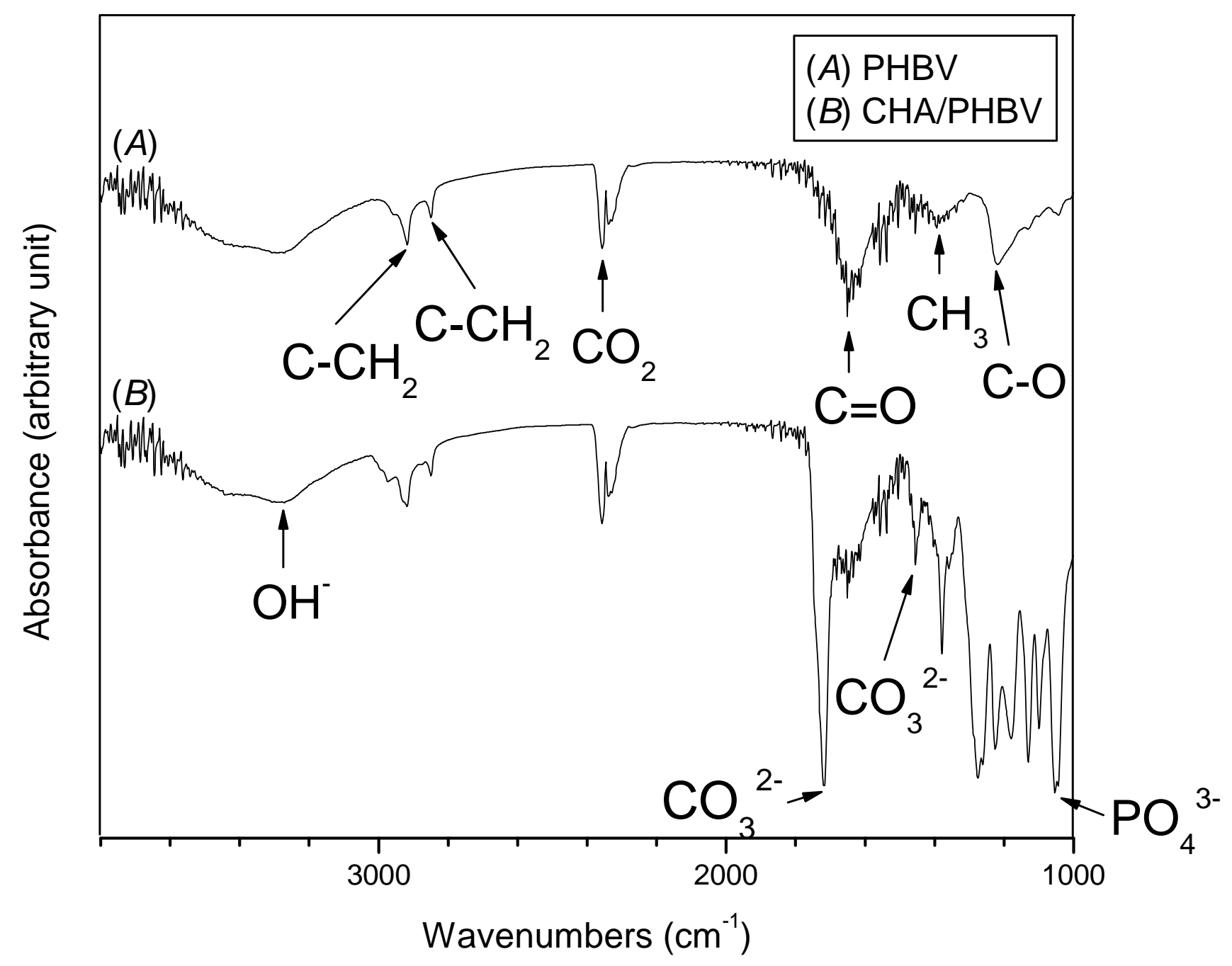

Figure 10. FTIR spectra of $(A)$ PHBV fibrous membranes, and $(B)$ CHA/PHBV nanocomposite fibrous membranes. 


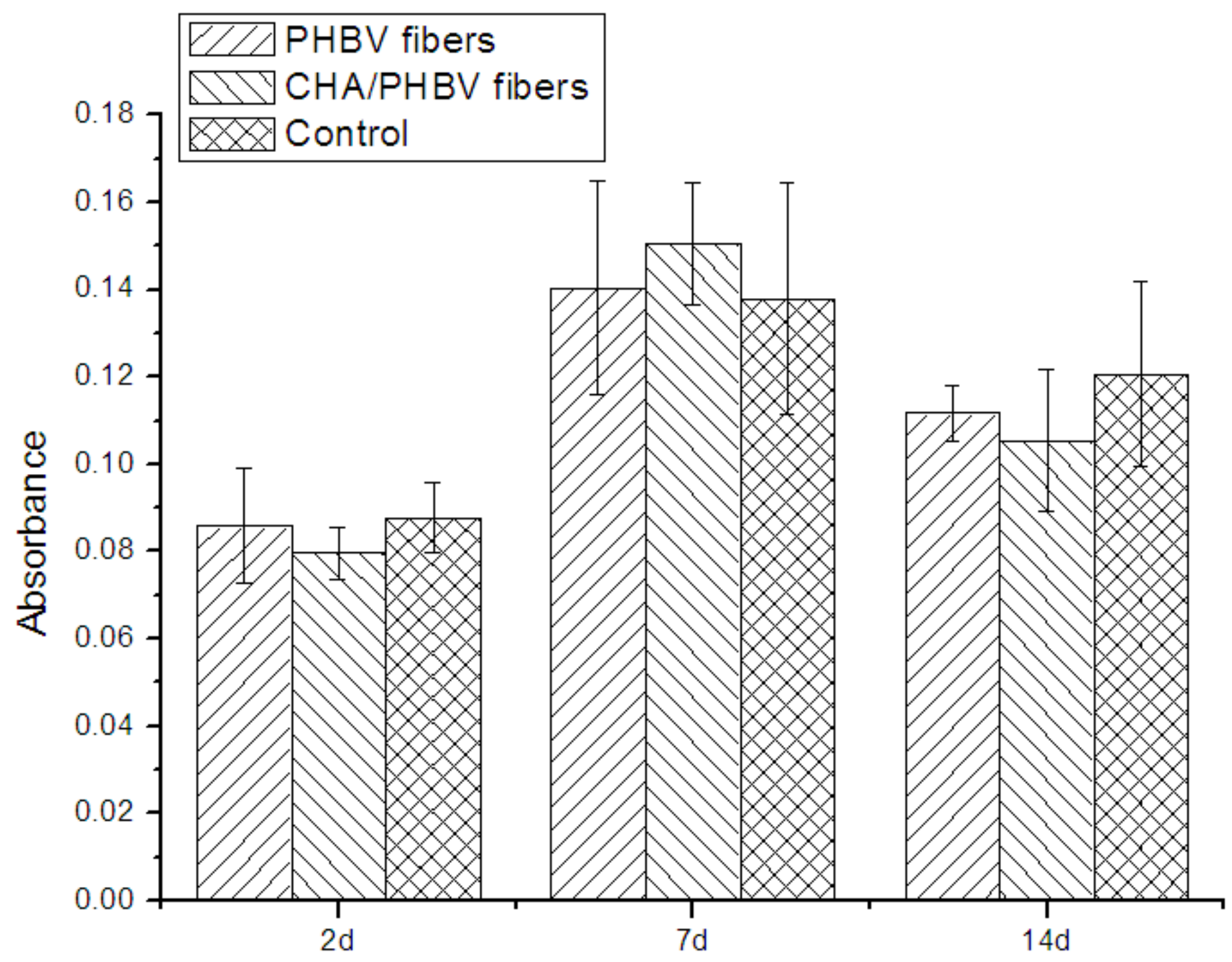

Figure 11. Proliferation of SaOS-2 cells seeded on both types of fibrous membranes (PHBV and CHA/PHBV) and the control as a function of cell culture time. 


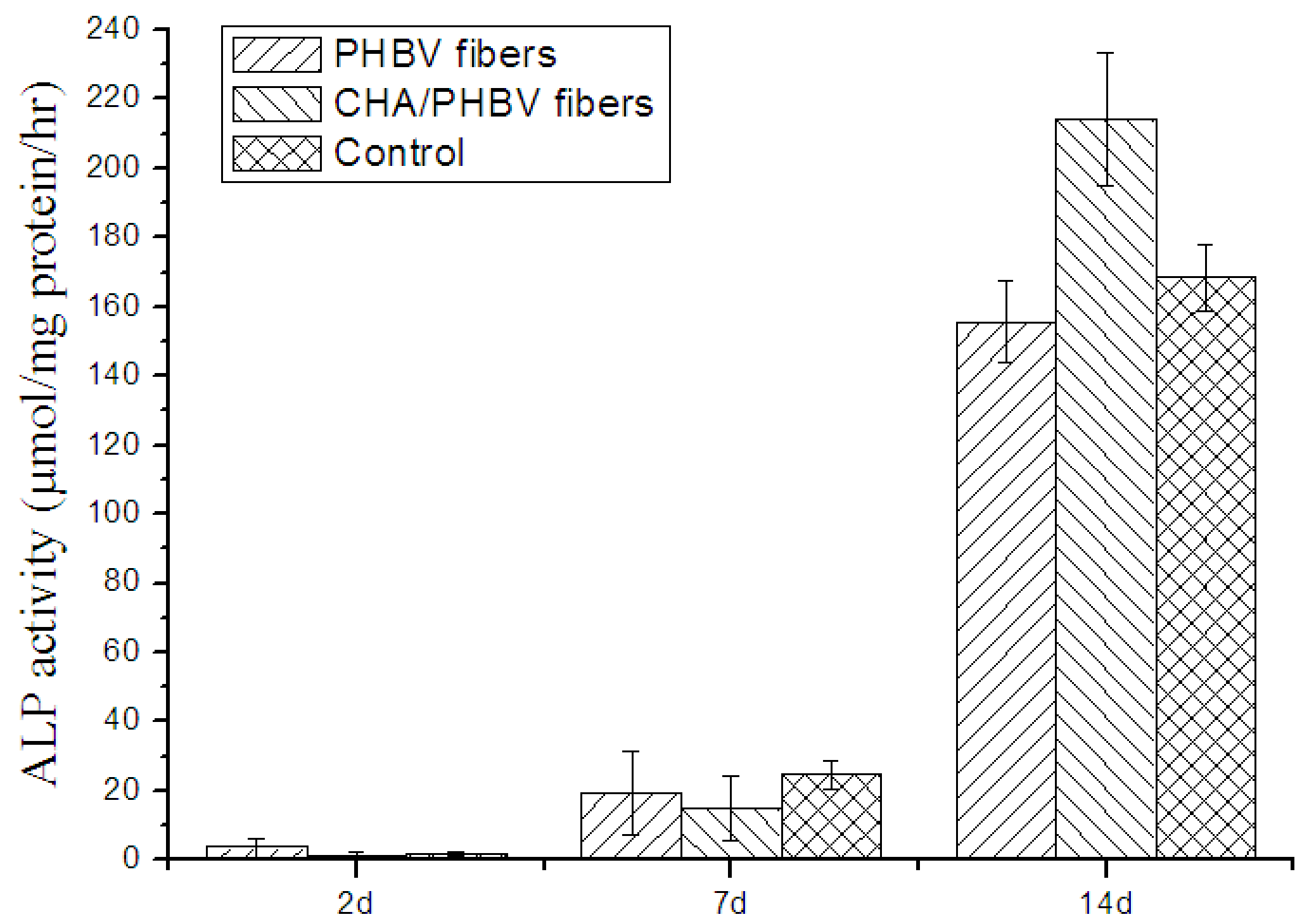

Figure 12. ALP activity of SaOS-2 cells seeded on both types of fibrous membranes (PHBV and CHA/PHBV) and the control as a function of cell culture time. 


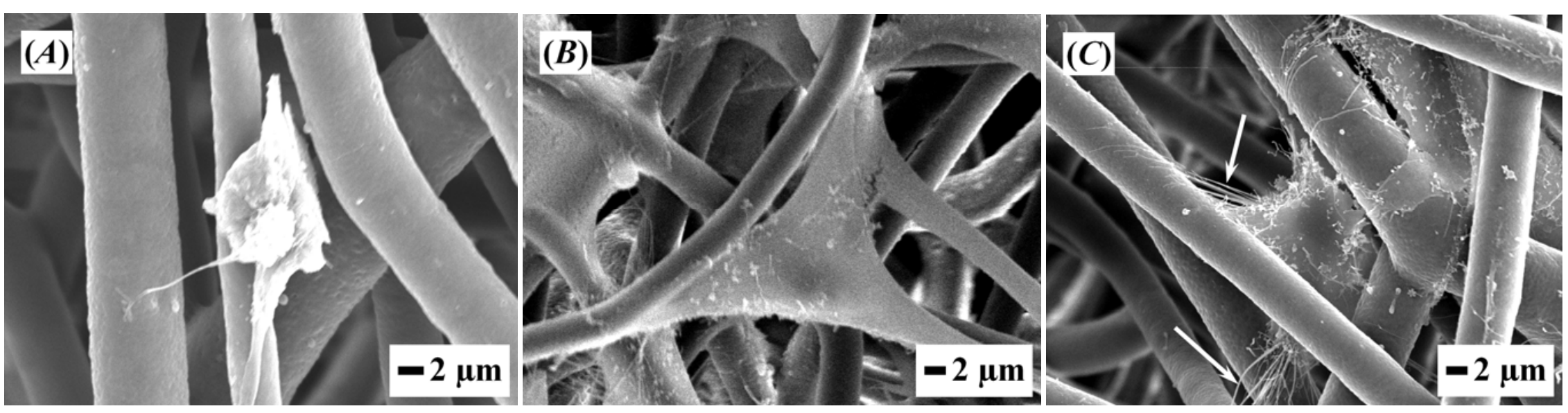

Figure 13. Morphology of SaOS-2 cells seeded on fibrous PHBV membranes after various cell culture times (white arrows pointing at filopodia): (A) 2 days; $(B) 7$ days; $(C) 14$ days. 


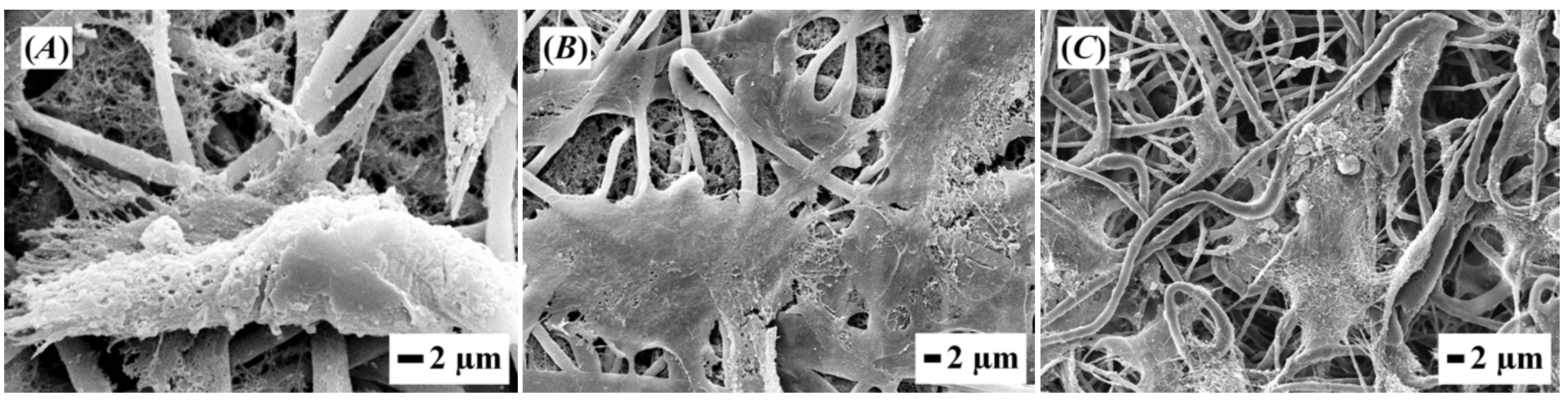

Figure 14. Morphology of SaOS-2 cells seeded on fibrous CHA/PHBV nanocomposite membranes after various cell culture times: $(A) 2$ days; $(B)$ 7 days; (C) 14 days. 


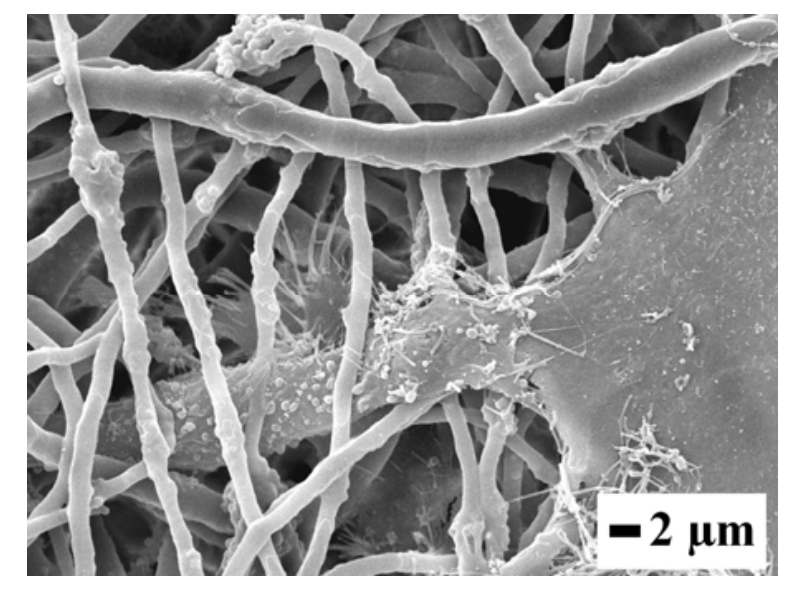

Figure 15. Penetration of SaOS-2 cell into fibrous PHBV membrane through interstitial pores. 